\title{
Managing A Rare Case of Multiple Complicated and Uncomplicated Tooth Fractures in A 13-Year-Old Patient: A Case Report
}

\author{
Aman Deep ${ }^{1}$ Seema Thakur ${ }^{2}$ Parul Singhal ${ }^{2}$ Deepak Chauhan ${ }^{2}$
}

\author{
'Department of Pediatric and Preventive Dentistry, Bhojia Dental \\ College and Hospital, Baddi, Solan, India \\ 2Department of Pediatric and Preventive Dentistry, HP Government \\ Dental College and Hospital, Shimla, India
}

\author{
Address for correspondence: Aman Deep, MDS, Department of \\ Pediatric and Preventive Dentistry, Bhojia Dental College and Hospital, \\ Baddi, Solan, Himachal Pradesh 173205, India \\ E-mail: amdsingh91@gmail.com
}

\begin{abstract}
While managing a case of indirect traumatic injuries, it becomes imperative that there is thorough evaluation of case as the injuries sustained can be hidden and are not outrightly seen as compared to direct injuries. Complicated crown fractures and crown-root fractures pose difficulties for dentists to establish adequate treatment plans because these fractures require multidisciplinary knowledge and approach for a correct case planning and prognosis. This case report discusses a case of traumatic injuries sustained by an individual in which multiple tooth fractures involving crown and root were seen in the posterior dentition in the both the arches. Although the literature discusses a lot of techniques for management of crown and root fractures, here we decided to treat the patient using one of the primitive techniques. The rationale for this lies in the fact that the teeth involved bear high masticatory load and do majority of masticatory function and hence the uses of this technique was thought to be efficient in restoring form and function. Treatment consisted of restoration of uncomplicated crown fractures with composite restorations while Complicated crown and root fractures were treated with gingivoplasty and osteotomy coupled with endodontic treatment and porcelain fused to metal crowns. Although managing this type of injuries using this method was relatively less time consuming but since the follow-up is yet to be evaluated, propagation of this technique as compared to other well-established technique cannot be done. However immediate post-operative signs showed positive response to restore form and function.
\end{abstract}

Keywords: Dental crowns, gingivectomy, porcelain, trauma, tooth fractures

\section{Introduction}

Cusps tend to deform and fracture when subjected to forces that are exerted over them.[1] The injuries that tooth sustain depends upon the factors such as energy, resilience and the morphology of the object causing the injury.[2] Additionally, direction of the forces exerted also plays a pivotal role in determining the types of trau- matic injury. Two types of forces are generally encountered direct trauma or indirect trauma. [3] When the teeth are struck against a surface, or an object strikes the teeth it is referred to as a direct trauma. However forceful closure of teeth due to blow on the chin is an example of indirect trauma. [4]

A plethora of studies testify to the fact that falls are a preliminary reason causative of traumatic injuries.[5]

How to cite this article: Deep A, Thakur S, Singhal P, Chauhan D. Managing A Rare Case of Multiple Complicated and Uncomplicated Tooth Fractures in A 13-Year-Old Patient: A Case Report. J Pediatr Dent 2021;7(1):00-00 
Guardsman fracture, or parade ground fracture are also some other example characteristic of causing indirect trauma to the jaws, cranium and the dentition.[6] As a protective mechanism periodontal ligaments (PDL), and the bone acts as a cushion that tend to dampen the effects of forces that have been placed over the tooth. However, when the threshold of the traumatic force exceeds that of the PDL, fracture of the hard tissues occur.[7] The forces generated generally get propagated along the long axis of the tooth and lead to fracture along either mesial-distal plane or bucco-lingual plane in vertical or oblique direction. Fractures involving transverse direction are more frequently seen in anterior teeth as compared to the posterior teeth.

In teeth such as maxillary premolars due to the anatomy of the tooth there are more chances that the teeth get fractured in bucco-lingual direction more often, small mesiodistal dimensions and high cusps are the factors resulting in fracturing of the palatal cusps in these teeth. $[2,8]$ Following is a case report that shows traumatic injuries sustained due to indirect trauma.

\section{Case Presentation}

A 13-year-old female patient reported to the outpatient department, who had fallen during annual day parade in the school. Patient reportedly got unconscious and had fallen on a dirt ground and hit her chin first. She was taken to the local government clinic where she was given first aid as she had abrasion injury on to her chin. She had reported to the department 3 days post injury. On extraoral examination, patient had a symmetrical face, with a convex profile.

An orthopantomogram was taken to rule out any jaw fracture, however no such finding was seen. A radiolucent line propagating on the mesial cusp was seen on the lower right permanent $1^{\text {st }}$ molar and fractured distal cusp of upper right $1^{\text {st }}$ permanent molar. Tooth fractures on left side of the dentition were not clearly evident over the orthopantomogram. (Fig. 1a)
However, on intraoral examination, patient had a permanent dentition, and well aligned maxillary and mandibular arches. The midline was shifted towards right side. In the maxillary arch, patient had sustained multiple posterior teeth fracture. Uncomplicated crown fractures were seen in 24 and 26 (FDI Notation) (Fig. 1b), while 15 sustained complicated crown fracture and 14 had complicated crown root fracture with fracture line extending 3 $\mathrm{mm}$ beyond the crest of the alveolar bone. (Fig. 1c) Additionally, in the mandibular arch patient had a couple of uncomplicated crown fractures wrt 36,46. (Fig. 1d) Also there was generalized stains and calculus present in maxillary and mandibular arches. Patient on the whole had a poor oral hygiene as she was not brushing her teeth post trauma and had a restricted mouth opening with no deviation on opening and closing.

The treatment consisted of extraction of the fractured palatal cusp of left maxillary $1^{\text {st }}$ premolar (Fig. 2a) under profound anesthesia using lidocaine with 1:80.000 adrenaline, whereas the immediate management of the left maxillary second premolar was done by placing a $0.004 \mathrm{X} 0.150 \mathrm{X} 2$ inch stainless steel band around the tooth so as to stabilize the fractured segment. Both the teeth sustaining fractures that involved the pulp were planned to undergo root canal therapy. (Fig. 2b) While Uncomplicated crown fractured teeth were planned for composite restorations (Ivoclar Vivadent Inc, USA). Tooth no. 46 in particular had fractured mesiolingual cusp with $0.5-1 \mathrm{~mm}$ of remaining dentin thickness, so indirect pulp capping with hard set calcium hydroxide cement (DY: Dycal, L.D. Caulk Co.) was done and later restored with composite restoration (Ivoclar Vivadent Inc, USA). (Fig. 2c, 2d) Multiple sitting root canal therapy was initiated in respect to left maxillary $1^{\text {st }}$ and $2^{\text {nd }}$ premolar, rubber dam application was difficult to achieve in this case however isolation was maintained using cotton rolls and low volume suction. Since the fractured palatal cusp of tooth 14 was extracted, gingivoplasty and osteotomy was done to expose the fracture line. A Bard Paker blade no. 12 and
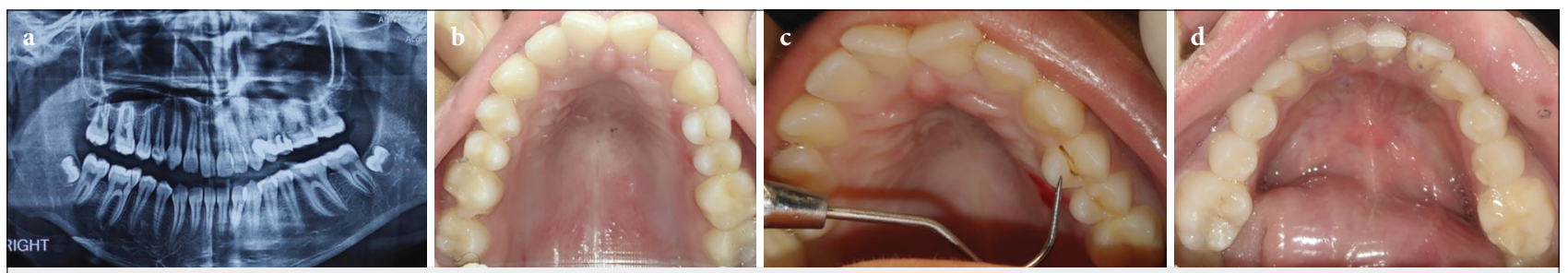

Figure 1. (a) Shows orthopantomograph of the patient showing radiolucent lines in posterior teeth on right side of maxillary and mandibular Arch. (b) Intraoral maxillary occlusal view showing fractured distolingual cusp of tooth 16 (FDI Notation), and palatal cusps of tooth no. 14, 24, 25. (c) Fractured palatal cusp wrt maxillary left first premolar. (d) Intraoral mandibular occlusal view of fractured right mesiolingual cusp 

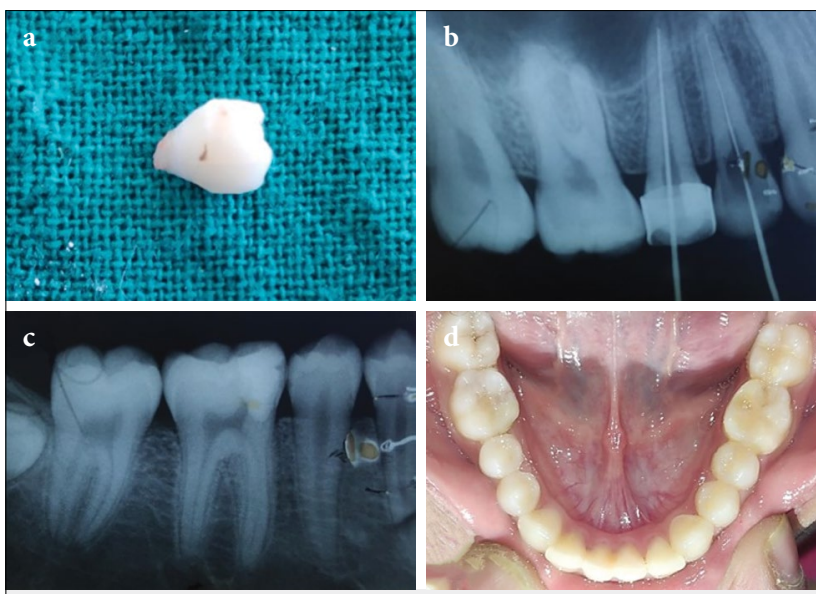

Figure 2. (a) Extracted fractured palatal cusp of left maxillary first premolar. (b) Intraoral periapical radiograph left maxillary posterior quadrant showing working length taken for endodontic procedure. (c) Intraoral periapical radiograph of right mandibular posterior quadrant showing composite restoration done on mandibular first molar. (d) Intraoral mandibular occlusal view showing multiple composite restoration done wrt tooth no. 36,46

tapered fissure diamond point (FO-21 MANI Inc) was used for gingivoplasty on the palatal aspect, while the alveolar crest on the palatal aspect was remodeled using low speed round carbide bur. The procedures were done to establish a biological width of $3 \mathrm{~mm}$ on the palatal aspect of right maxillary $1^{\text {st }}$ premolar. Both the teeth were obturated using gutta-percha and restored with glass ionomer cement (Ketac Molar, 3M Company) and were asked to follow up after 2 weeks. (Fig. 3a) Using a Peeso reamer size 3 (Mani, INC, Japan) a post space was prepared for the palatal canal and $5 \mathrm{~mm}$ of gutta-percha was allowed to remain in the canal space for providing apical seal. A size 2 glass fiber post (Reforpost, Angelus Ind. E Com Ltda. Londrina, PR Brazil) with $1.4 \mathrm{~mm}$ diameter was luted into the canal and reinforced glass ionomer cement was used to build-up the core. (Fig. 3b, $3 \mathrm{c}$ ) Both, left maxillary $1^{\text {st }}$ and $2^{\text {nd }}$ premolar were prepared for porcelain fused to metal (PFM) crowns. The patient was given interim, chemically cured acrylic crowns which were luted with zinc oxide eugenol cement until porcelain fused to metal crowns were fabricated by the lab. The PFM crowns were later cemented using Type I luting glass ionomer cement (Shofu), occlusion was confirmed (Fig. 3d) and postoperative radiographs were taken. (Fig. 3e, 3f, 3g) The patient was put for recall every 6 months.

\section{Discussion}

Uncomplicated crown fractures are relatively easier to treat as compared to complicated crown root fractures. While uncomplicated fractures need simply restorative procedures for reestablishing form and function, several therapeutic procedures can be advocated to treat teeth with complicated crown root fracture, depending on fracture location.[9] Subgingival or infraosseous fractures include treatment modalities such as orthodontic or surgical extrusion, gingivectomy, gingivoplasty with osteotomy and intentional replantation.[10] The main objective irrespective of the treatment modality is to expose the fracture line supragingivally, so that clinical restoration can be done without blood or saliva contamination.[8]
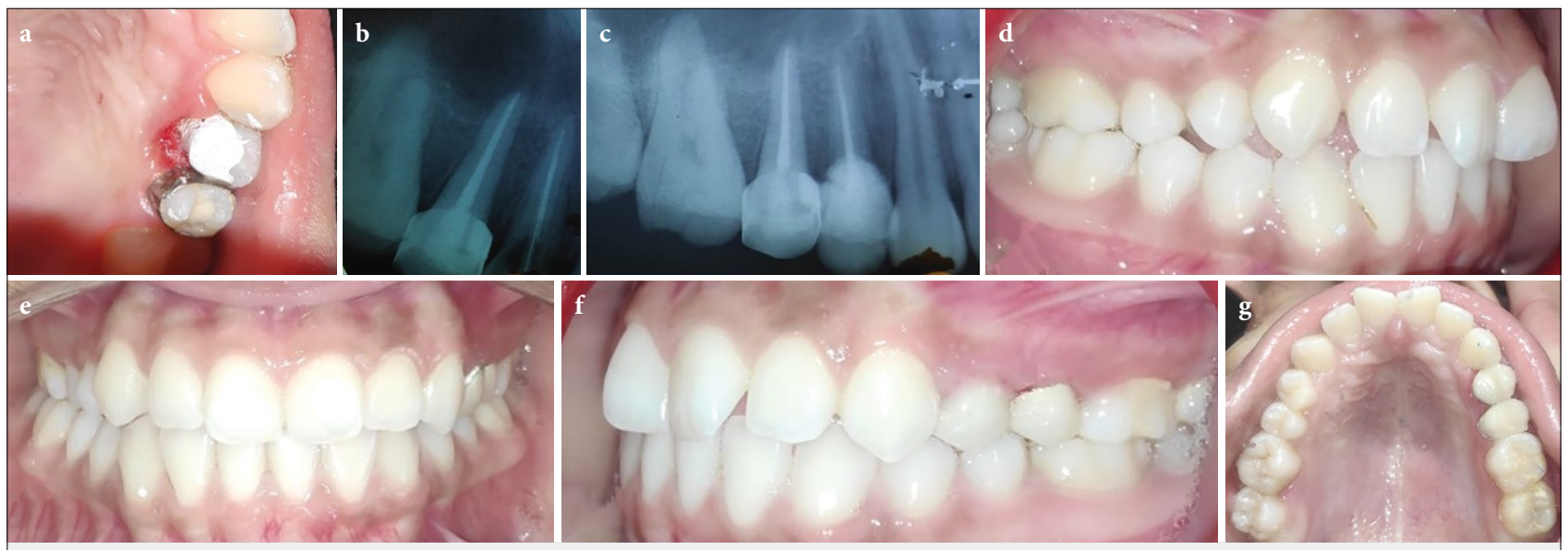

Figure 3. (a) Reinforced glass ionomer restoration done wrt tooth no. 24 post gingivoplasty and osteotomy. (b) Intraoral periapical radiograph showing placement of fiber post in palatal pulp canal space in left maxillary first premolar. (c) Post-operative radiograph left maxillary posterior quadrant. (d) Post-operative right lateral intraoral view (e) Post-operative frontal intraoral view (f) Post-operative left lateral intraoral view showing porcelain fused to metal crowns over left maxillary first and second premolar in occlusion (g) Post-operative maxillary occlusal view showing porcelain fused to metal crowns luted over left maxillary first and second premolar 
The decision to treat the patient in such a way was made based on exclusion of other treatment options. The exposure of the fracture dental margin was achieved with gingivoplasty and osteotomy on the palatal aspect of left maxillary $1^{\text {st }}$ premolar and later obturation and restoration was done in the same appointment. The advantage of such a technique is that it is rapid and require single appointment. Moreover, this technique is considered useful in cases where posterior dentition is involved and procedure taking place in non-esthetic zones.[11] While the limitation of the technique is decreased crown root ratio, encroachment into the biological width and periodontal related problems. The technique cannot be used in anterior dentition due major esthetic concerns.[12]

Orthodontic extrusion to expose the fracture margin could not be done as the adjacent tooth had also undergone injury and did not provide sufficient support for extrusion of the tooth. Additionally, the extracted palatal cusp of the premolar did not adapt well to the fracture line due multiple communited fractures and hence fragment reattachment could not be done. As reported in a case by Koparal et al[13] good adaptation of the reattachment fragment is necessary to provide sealing effect and minimize plaque retention. Additionally, a major drawback of reattachment in posterior teeth is that palatal cusps being the functional cusps are subjected to heavier loads and can easily detach under mastication. [14,15] Hence reattachment procedure was not considered.

Crown root fractures involving posterior teeth due to trauma is rarely seen, majority of literature discusses these types of fractures either in tooth that have undergone endodontic therapy or have large amalgam restoration. Also, there are a lot of case report discussing posterior tooth fracture due to trauma in primary dentition. [16,17]

A report by Gonzalez-Lopez et al[18] discusses similar management of tooth fracture in which the palatal gingiva of the fractured maxillary premolar was remodeled and later porcelain fused to metal crown was placed over the tooth. The study at 7 year follow up showed satisfactory esthetics and functional outcomes with good periodontal health.

Caliskan et al[19] considered the surgical technique a success in extruding teeth with crown root fractures because no clinical signs of periapical damage, ankylosis or marginal bone loss were observed. In their study, only $5 \%$ of the cases presented external root resorption within 3 years. In literature orthodontic extrusion coupled with surgical procedure for esthetic rehabilitation is the preferred treatment modalities among the practioners, when managing traumatic injuries in anterior dentition or esthetic zone.[20]

Recently other treatment option have also been reported in management of crown root fractures which include 180 degree rotation of the tooth to expose fracture line[21], and also intentional replantation of tooth after fragment reattachment was done extraorally.[22]

\section{Conclusion}

Management of crown and root fracture in posterior dentition using this technique was relatively easy and quick, but it must be noted that there is paucity of data to support this type of intervention mainly due to fact that anterior dentition is more commonly affected by traumatic injuries as compared to posterior counterpart resulting in less reported cases. However, the long-term prognosis of such technique is a topic, still to be explored.

\section{Clinical significance}

- Whenever trauma is reported always check for cracks and fractures in posterior dentition, especially when anterior teeth are intact.

- Although this technique is less novel, management using this technique is a viable treatment option especially when the affected area is in non-esthetic zone.

Financial Disclosure: Nil.

Conflict of Interest: None declared.

\section{References}

1. Rock WP, Gordon PH, Friend LA, Grundy MC. The relationship between trauma and pulp death in incisor teeth. Br Dent J 1974;136(6):236-239 doi:10.1038/sj.bdj.4803162

2. Andreasen JO. Etiology and pathogenesis of traumatic dental injuries. A clinical study of 1,298 cases. Scand J Dent Res 1970;78(4):329-342 doi:10.1111/j.1600-0722.1970.tb02080.x

3. Bennett DT. Traumatized anterior teeth. Br Dent J 1963;115:309311

4. Oikarinen K. Pathogenesis and mechanism of traumatic injuries to teeth. Endod Dent Traumatol 1987;3(5):220-223 doi:10.1111/j.1600-9657.1987.tb00626.x

5. Nagarajappa R, Ramesh G, Uthappa R, Kannan SPK, Shaikh S. Risk factors and patterns of traumatic dental injuries among Indian adolescents. J Dent Sci 2020;15(1):96-103 doi:10.1016/j. jds.2019.07.003

6. Chopra LB, Lingappa A, Singh M, Anshul A. Mandibular fractures and their radiographic diagnosis. Acta Sci Dent Sci 2020;4(7):161-171 
7. Nanci A, Bosshardt DD. Structure of periodontal tissues in health and disease. Periodontol 2000 2006;40:11-28 doi:10.1111/j.16000757.2005.00141.x

8. Andreasen JO, Andreasen FM, Tsukiboshi M. Crown-root fractures. In: Andreasen JO, Andreasen FM, Andersson L, ed. Textbook and color atlas of traumatic injuries to the teeth, 4th edn. Oxford: Blackwell Munksgaard; 2007:314-36

9. Vignesh R, Sharmin D, Rekha CV, Annamalai S, Baghkomeh PN. Management of complicated crown-root fracture by extraoral fragment reattachment and intentional reimplantation with 2 years review. Contemp Clin Dent 2019;10(2):397-401 doi:10.4103/ccd.ccd_671_18

10. Sharma D, Garg S, Sheoran N, Swami S, Singh G. Multidisciplinary approach to the rehabilitation of a tooth with two trauma episodes: systematic review and report of a case. Dent Traumatol 2011;27(4):321-326 doi:10.1111/j.16009657.2011.01006.x

11. Wang Z, Heffernan M, Vann WF Jr. Management of a complicated crown-root fracture in a young permanent incisor using intentional replantation. Dent Traumatol 2008;24(1):100-103 doi:10.1111/j.1600-9657.2006.00487.x

12. Koyuturk AE, Malkoc S. Orthodontic extrusion of subgingivally fractured incisor before restoration. A case report: 3-years follow-up. Dent Traumatol 2005;21(3):174-178 doi:10.1111/j.16009657.2005.00291.x

13. Koparal E, Ilgenli T. Reattachment of a subgingivally fractured central incisor tooth fragment: report of a case. J Clin Pediatr Dent 1999;23(2):113-115

14. Chan CP, Tseng SC, Lin CP, Huang CC, Tsai TP, Chen CC. Vertical root fracture in nonendodontically treated teeth--a clinical report of 64 cases in Chinese patients. J Endod 1998;24(10):678681 doi:10.1016/s0099-2399(98)80154-4
15. Cohen S, Berman LH, Blanco L, Bakland L, Kim JS. A demographic analysis of vertical root fractures. J Endod 2006;32(12):1160 1163 doi:10.1016/j.joen.2006.07.008

16. Deshpande A, Patel J, Sujan SG, Mallikarjuna R. Crown fracture of the mandibular second primary molars in a 4-year-old child. BMJ Case Rep 2013;2013:bcr2012008475 doi:10.1136/bcr-2012-008475

17. Hariharan VS, Rayen R. Case report: management of crownroot fracture in lower first primary molar caused by injury to the chin: report of an unusual case. Eur Arch Paediatr Dent 2012;13(4):217-220 doi:10.1007/BF03262873

18. González-López S, González-Villafranca MP, Bolaños-Carmona MV, Menéndez-Nuñez M. A new approach to endodontic treatment and operative procedure in nonendodontically treated posterior crown root fractures. Oral Surg Oral Med Oral Pathol Oral Radiol Endod 2009;108(5):e106-e110 doi:10.1016/j. tripleo.2009.06.014

19. Caliskan MK, Turkun M, Gomel M. Surgical extrusion of crownroot-fractured teeth: a clinical review. Int Endod J 1999;32(2):146151 doi:10.1046/j.1365-2591.1999.00199.x

20. Faria LP, Almeida MM, Amaral MF, Pellizzer EP, Okamoto R, Mendonça MR. Orthodontic extrusion as treatment option for crown-root fracture: Literature review with systematic criteria. J Contemp Dent Pract 2015;16(9):758-762 doi:10.5005/jp-journals-10024-1753

21. Faghihian R, Eshghi A, Mosleh H, Akhlaghi N. Management of complicated crown-root fracture in central incisors using intentional replantation with 180 rotation: A case report. Dent Hypotheses 2017;8:113-116

22. Vignesh R, Sharmin D, Rekha CV, Annamalai S, Baghkomeh PN. Management of Complicated Crown-Root Fracture by ExtraOral Fragment Reattachment and Intentional Reimplantation with 2 Years Review. Contemp Clin Dent 2019;10(2):397-401 doi:10.4103/ccd.ccd_671_18 